\title{
Acerca dos processos compensatórios no desenvolvimento da criança mentalmente atrasada'
}

Lev Semionovich Vigotski

\section{Resumo}

Neste artigo, originalmente apresentado por Vigotski em um congresso em 1931 e posteriormente convertido em texto escrito a partir de anotações taquigráficas, destacase a importância dada pelo autor aos riscos de que pesquisas e programas educacionais dirigidos à criança com deficiência focalizem processos biológicos e disfunções primordiais em detrimento de funções psicológicas superiores. Seu argumento principal é o de que processos compensatórios e caminhos indiretos podem promover o desenvolvimento. Tais processos e caminhos relacionam-se com a inserção das crianças em diversos ambientes culturais e são suscetíveis à ação pedagógica. Destaca-se ainda o fato de que, para Vigotski, os objetivos e tarefas da educação especial devem corresponder àqueles da escola regular, isto é, preparar a criança para enfrentar as diversas demandas da vida em sociedade.

\section{Palavras-chave}

Vigotski - Defectologia - Educação especial - Deficiência - Compensação Desenvolvimento - Aprendizagem.

1 - (Esta e todas as demais notas são Notas das Tradutoras)- Este artigo, inédito no Brasil, foi traduzido diretamente do russo por Priscila Nascimento Marques - priscilanm@gmail.com, Denise Regina Sales - denise.sales@ufrgs.br e Marta Kohl de Oliveira - mkdolive@usp.br (VIGOTSKI, 1983). Foi originalmente apresentado por Vigotski em um congresso de educadores de escolas auxiliares em 23 de maio de 1931 e depois transformado em texto escrito a partir de anotações taquigráficas. Após sua publicação em russo no quinto volume das Obras escolhidas, em 1983, 0 texto foi incluído em traduções feitas nos Estados Unidos (1993) e na Espanha (1997). Os termos defectologia, criança mentalmente atrasada, criança oligofrênica, débil, idiota, imbecil, defeito, utilizados no artigo, foram mantidos na presente tradução por corresponderem à terminologia utilizada no início do século XX, quando Vigotski produziu seus textos. Atualmente, seriam equivalentes a expressões como deficiência, educação especial, criança com deficiência. É inegável o interesse histórico e a importância, no contexto brasileiro, de traduções diretas da obra vigotskiana. 


\section{Compensatory processes in the development of the retarded child}

\section{Abstract}

This article was originally presented by Vygotsky in a Conference in 1931 and later turned into a written text with basis on tachygraphic notes. The author focuses on the risks of research and educational programs addressed to children with special needs to focus on biological processes and basic dysfunctions, instead of working with higher psychological functions. His main argument is that compensatory processes and indirect paths may promote development. Such processes and paths are related to the inclusion of children in diversified cultural environments and are susceptible to educational action. For Vygotsky, goals and tasks of special education should be similar to the ones of regular school, that is, to prepare children to face different demands of social life.

\section{Keywords}

Vygotsky - Defectology - Special education - Disability - Compensation - Development - Learning.

1.

A clínica, a que devemos a identificação e o diagnóstico das crianças mentalmente atrasadas, interessou-se muito pouco pelo desenvolvimento da criança marcada por esse atraso. Pela própria essência das tarefas práticas que se apresentam à clínica médica, ela não podia se aprofundar nas questões do desenvolvimento da criança, uma vez que o atraso infantil pertence ao conjunto das formas clínicas pouco ou nada suscetíveis à ação terapêutica. Essas formas de desenvolvimento incompleto não se tornaram objeto de pesquisa aprofundada na clínica: para isso não havia nem estímulos práticos, nem motivação por parte de nenhuma tendência do pensamento clínico. À clínica interessava principalmente a possibilidade de identificação de sinais, com a ajuda dos quais fosse possivel reconhecer o atraso mental, definir essa forma de deficiência e distingui-la de outros quadros semelhantes - e só. Foi com esses objetivos que a clínica levantou o problema do desenvolvimento da criança oligofrênica. Ela estabeleceu que o oligofrênico se desenvolve, e não se degrada, como as crianças doentes mentais. Esse fato geralmente é elencado ao lado de outros sintomas. Com a ajuda desses sintomas, o atraso mental infantil leve distingue-se e diferencia-se de outras formas externamente semelhantes a ele.

Em função da abordagem clínica ao problema do atraso mental, tomaram-no como coisa e não o examinaram como processo. Interessavam os sinais de estabilidade, de constância, enquanto a dinâmica da criança mentalmente atrasada, as leis de seu desenvolvimento e sua coincidência com as leis de desenvolvimento da criança normal - 
tudo isso permaneceu e, em essência, não poderia deixar de permanecer, fora do campo de visão da clínica.

A pedagogia médica, pedagogia da escola auxiliar², recebeu da clínica as noções elementares sobre a natureza do atraso mental e tentou construir sua própria prática com base no quadro desenhado a partir do resultado do estudo clínico. Inicialmente isso parecia suficiente, pois quando a escola burguesa se deparou com o problema e o fato do atraso mental, diante dela surgiram tarefas negativas, desfavoráveis - colocar uma barreira na entrada da escola normal e com sua ajuda selecionar as crianças incapazes de lá aprender e aquelas que não querem estudar. Essas tarefas também se colocavam para Alfred Binet ${ }^{3}$ quando ele abordou o diagnóstico do atraso mental.

Qualquer um entende que não há nada mais precário do que selecionar por meio de traços negativos. Ao fazermos essa seleção, corremos o risco de escolher e reunir em um único grupo crianças que, em seus aspectos positivos, terão pouco em comum. Se nos pusermos a separar cores que não sejam pretas, apenas por esse traço distintivo, teremos uma mistura variegada: haverá cores vermelhas, amarelas e azuis, simplesmente porque não são pretas. A prática pedagógica de massas (europeia e americana) demonstrou: a orientação por traços negativos levou justamente àquilo que aconteceu com aqueles que resolveram separar cores por um traço negativo, ou seja, as crianças selecionadas revelaram-se profundamente heterogêneas em constituição, estrutura, dinâmica, possibilidades e causas que as levaram a essa condição. Até para a escola burguesa essas orientações são insuficientes pois, quando surgiu a questão do ensino e da educação das crianças mentalmente atrasadas, de sua condução a um nível, ainda que mínimo, das exigências que lhe são colocadas, viu-se que não era possível identificar o atraso mental com base numa definição puramente negativa. Não devemos nos apoiar naquilo que falta à criança, naquilo que ela não é, mas é preciso ter alguma noção, ainda que vaga, daquilo que ela possui, do que ela própria apresenta. Quanto a isso a escola burguesa fez extremamente pouco.

Atualmente nossa escola, que se encontra diante de enormes tarefas de significado histórico, realiza uma reviravolta decisiva em toda a teoria e prática de ensino e educação da criança normal e da atrasada. Nossa escola auxiliar sente a insuficiência das orientações teóricas básicas, daquela fundamentação científica que se pode obter das fontes sobre as quais falamos até aqui. E o que primeiramente surge diante de nós são novos objetivos e tarefas de natureza prática que se apresentam para o estudo da criança mentalmente atrasada. Não o estudo pelo estudo, mas para encontrar as melhores formas de ação prática, para resolver a tarefa histórica da real superação do atraso mental, dessa enorme calamidade social, remanescente da estrutura de classes da sociedade. Essa tarefa subordina o estudo às necessidades da prática que se apresentam agora e exigem uma abordagem positiva e diferenciada no estudo das crianças mentalmente atrasadas, isto é,

\footnotetext{
2- 0 termo escola auxiliar refere-se a escolas especiais para crianças com deficiência mental. A seleção dos estudantes era realizada por uma comissão médico-pedagógica especializada, formada por psiquiatras infantis e psicólogos.

3- Alfred Binet (1857-1911), pesquisador francês frequentemente citado por Vigotski, dedicou-se ao desenvolvimento de instrumentos para medida de capacidades intelectuais. Com Théodore Simon (1873-1961), desenvolveu as famosas escalas Binet-Simon, para avaliação da inteligência, nas quais foi introduzido o conceito de idade mental.
} 
um estudo do ponto de vista daquilo que caracteriza essa criança em termos positivos e contribui para o desmembramento da massa geral das crianças mentalmente atrasadas.

Atualmente até os melhores cientistas burgueses reconhecem que falar que a criança é mentalmente atrasada é o mesmo que falar que uma pessoa está doente, mas não dizer qual é sua doença. É possível constatar o fato do atraso, mas é difícil determinar a essência, a origem e o destino do desenvolvimento dessa criança. Em consequência disso, a principal tarefa que se coloca diante dos pesquisadores do atraso mental é tentar contribuir para o estudo do desenvolvimento da criança mentalmente atrasada e das leis que regem esse desenvolvimento.

Sendo assim, parece-me que hoje devo me concentrar em três questões que constituirão o conteúdo da minha apresentação.

Primeira questão: o que, no desenvolvimento da criança mentalmente atrasada, trabalha não contra nós, mas a nosso favor, isto é, quais são os processos que surgem no próprio desenvolvimento da criança mentalmente atrasada que levam à superação do atraso, à luta contra ele, e que conduzem a criança a um degrau mais elevado? Segunda questão: qual é a estrutura e qual é a dinâmica do atraso mental como um todo? Por certo o quadro do atraso mental não se esgota nos processos que trabalham a nosso favor. Para compreender o significado e o lugar desses processos, é preciso compreender seu lugar e significado na estrutura geral do atraso mental. A terceira questão consiste nas conclusões pedagógicas máximas decorrentes da explicitação da primeira e da segunda. Dessa forma, explicitarei brevemente essas três questões fundamentais.

A premissa geral da qual eu parto e que, me parece, deve ser colocada na base do estudo científico do desenvolvimento do indivíduo mentalmente atrasado é a noção da coincidência das leis do desenvolvimento da criança normal e da mentalmente atrasada. É claro que essa posição, de modo algum, nega o fato de que as leis do desenvolvimento da criança mentalmente atrasada adquirem uma expressão específica qualitativamente distinta e que a tarefa não se limita à constatação de sua coincidência, mas em mostrar como as leis de desenvolvimento da criança, únicas em essência e por princípio, adquirem sua expressão concreta e particular, quando aplicadas à criança atrasada. Essa é a premissa primeira e central sobre a qual é preciso falar desde o início.

A questão metodológica consiste no seguinte. Até agora prevaleceu a noção adotada no ocidente que estipula a existência de duas formas de educação de crianças determinadas por razões biológicas e por razões sociais. Pressupunha-se que, na presença de deficiências biológicas, as crianças se desenvolvem por trilhos biológicos e para elas pode ser revogada a lei do desenvolvimento e formação social, que determina o desenvolvimento de qualquer criança normal. Essa noção mecanicista é metodologicamente inconsistente. Desde o início é necessário chegar a um acordo sobre a posição básica, sem cuja aceitação todo o resto ficaria teoricamente infundado. Essa posição geral refere-se à correlação entre as regularidades sociais e biológicas no desenvolvimento infantil. A dificuldade na compreensão do desenvolvimento da criança atrasada surge porque o atraso foi tomado como coisa e não como processo. Isso encerrava o problema do desenvolvimento da criança atrasada. Daqui surgiu a noção de que é indubitável a existência de uma perturbação primária na oligofrenia e de que ela é o fundamento e o 
condutor de todo o desenvolvimento da criança. Entretanto, do ponto de vista dialético, não há noção mais equivocada e falsa do que essa, pois precisamente no processo de desenvolvimento, o primário, aquilo que surge no estágio inicial de desenvolvimento, é repetidamente removido pelas novas formações qualitativas que surgem.

Quanto ao conceito de remoção (ou superação) das regularidades, permitam-me dizer duas palavras. 0 termo remoção tem sido às vezes traduzido incorretamente. Origina-se do alemão enterrar (aufheben), mas tem nesse idioma duplo significado, assim como a palavra enterrar tem para nós duplo significado. Quando se diz enterrar em relação à regularidade orgânica, isso não significa que ela deixou de existir, mas sim que em algum lugar ela está preservada, encontra-se em segundo plano, se mantém no interior de algo, recuou ao segundo plano em comparação às regularidades surgidas em etapas posteriores. Por isso é evidente que as regularidades biológicas, primordiais para a determinação da etapa inicial do desenvolvimento dos mentalmente atrasados, estão enterradas, não destruídas, mas removidas do processo de desenvolvimento da criança mentalmente atrasada.

$\mathrm{Na}$ qualidade de sinais básicos, que estão no primeiro plano, é preciso estudar as regularidades justamente desse segundo tipo; essas são as premissas básicas das próximas ideias que vou desenvolver.

Permitam-me passar à primeira parte de nossa conversa, à questão dos processos que, no desenvolvimento dos indivíduos mentalmente atrasados, trabalham a nosso favor. Será que esses processos existem? No desenvolvimento das crianças mentalmente atrasadas, assim como no desenvolvimento de qualquer criança marcada por essa ou aquela deficiência, há processos que surgem do fato de que o organismo e a personalidade da criança reagem às dificuldades com as quais se defrontam, reagem à própria deficiência e, no processo de desenvolvimento, de adaptação ativa ao meio, produzem uma série de funções, com ajuda das quais compensam, equilibram, suprem a deficiência. Eu penso que essa questão diz respeito a uma noção biológica geral tão clara que quase não requer um desenvolvimento mais detalhado.

Para a educação da criança mentalmente atrasada é importante saber como ela se desenvolve; não são importantes por si só a deficiência ou a incompletude em si, o defeito, a falha; importa a reação que surge na personalidade da criança no processo de desenvolvimento em resposta à dificuldade com a qual ela se defronta e que decorre dessa deficiência. A criança mentalmente atrasada não é feita apenas de lacunas e defeitos, seu organismo como um todo se reconstrói. Toda a personalidade equilibra-se, é compensada por processos de desenvolvimento infantil.

É importante saber não só que doença a pessoa tem, mas que pessoa tem determinada doença. 0 mesmo é válido para a deficiência e os defeitos. Para nós, importa saber não apenas qual defeito foi medido com precisão em determinada criança, o que nela está afetado, mas também qual criança tem certo defeito, isto é, que lugar a deficiência ocupa no sistema da personalidade, que tipo de reconstrução ocorre, como a criança enfrenta sua própria deficiência. Não foi possível revelar os processos da doença enquanto não se compreendeu que o próprio organismo luta contra ela, que há sintomas de duas ordens: de um lado sintomas de perturbação das funções, de outro, sintomas da luta do organismo contra as perturbações. 
0 mesmo acontece no campo do estudo da criança com desenvolvimento anormal: enquanto não se aborda seu estudo do ponto de vista das perturbações em seu desenvolvimento, do ponto de vista do impacto compensatório dos processos de desenvolvimento, não se obtém uma compreensão completa, correta, adequada dessa criança.

Para deter-me concretamente naqueles mecanismos e regularidades que regem o aparecimento e desdobramento de processos compensatórios, devo falar brevemente sobre o significado teórico e o conceito do próprio princípio da compensação. Aplicado ao desenvolvimento da criança mentalmente atrasada, esse princípio foi muito pouco trabalhado precisamente no aspecto teórico, fundamental.

No início, a uma série de pesquisadores, e a mim inclusive, parecia que a maior conquista na compreensão dos processos compensatórios na criança mentalmente atrasada seria identificá-los e estabelecer a base factual dessa concepção sobre os processos compensatórios. A elaboração teórica da noção da compensação está longe de ser suficiente, inclusive no campo das ciências que operam com essa noção e que estão mais desenvolvidas do que o estudo da criança mentalmente atrasada. Mas estão claras algumas concepções fundamentais, que devem indicar a linha metodológica correta para nossa compreensão do princípio da compensação e à luz das quais devemos examinar o material e podemos falar sobre elas de forma esquemática.

A questão primordial e básica com que nos deparamos na compreensão do problema da compensação na criança mentalmente atrasada é o conceito da própria natureza do fenômeno que, como veremos, pode ser dupla.

Alguns consideram que o único e exclusivo fundamento dos processos compensatórios é a reação subjetiva da personalidade da criança na situação criada como consequência do defeito. Essa teoria pressupõe que a fonte única e imprescindível do surgimento dos processos compensatórios do desenvolvimento é a tomada de consciência da criança sobre sua deficiência, o surgimento do sentimento de inferioridade. A partir dele, da consciência da própria deficiência, aparece o desejo reativo de vencer esse sentimento difícil, superar a deficiência tornada consciente, elevar-se a um nível superior.

Exatamente com base nisso, a escola adleriana, na Áustria ${ }^{4}$, e a escola belga ${ }^{5}$ negam à criança mentalmente atrasada a possibilidade do desenvolvimento intensivo de processos compensatórios. 0 raciocínio dos defectologistas é o seguinte: para o surgimento da compensação é necessário que a criança sinta a própria deficiência e tome consciência dela. Mas, para a criança mentalmente atrasada, a dificuldade reside em que ela se relaciona consigo mesma de forma muito pouco crítica para que possa tomar consciência de sua própria deficiência e tirar uma conclusão eficaz para a superação de seu atraso. A esse respeito são interessantes as pesquisas empíricas publicadas por De Greeff ${ }^{6}$ sobre o desenvolvimento da criança mentalmente atrasada. Ele estabeleceu os sinais que se

4- Alfred Adler (1870-1937), médico e psicólogo austríaco. A Escola Adleriana é considerada uma escola de psicanálise, apesar das divergências de Adler com Freud. 0 próprio Adler rotula sua abordagem como psicologia individual, em que busca compreender cada pessoa como uma totalidade integrada em um sistema social.

5- A psicanálise belga desenvolveu-se no início do século XX como em outros países da Europa, mas nunca chegou a encontrar sua autonomia. Não fica claro a que escola Vigotski se refere aqui, já que a Sociedade Belga de Psicanálise só foi fundada na década de 1960. Trata-se possivelmente de uma referência ao pesquisador belga De Greeff, por ele mencionado em seguida.

6- Étienne De Greeff (1898-1961), médico belga, professor de criminologia, autor de obras sobre psiquiatria. 
convencionou chamar de sintomas de E. de Greeff e que consistem no fato de que, entre crianças com atraso mental, observa-se um juízo elevado sobre si. Se for solicitado a essa criança fazer uma avaliação comparativa de si, de seus companheiros, de seu professor, ela revela a tendência de se considerar a mais inteligente. Ela não reconhece o próprio atraso e, devido a seu elevado juízo sobre si, o desenvolvimento de processos compensatórios fica dificultado, se não reduzido a zero, pois a criança mentalmente atrasada está satisfeita consigo mesma, não nota a própria deficiência e, consequentemente, está privada daquela dolorosa experiência de sentimento de inferioridade que se encontra na base da formação dos processos compensatórios em outras crianças.

Outra concepção de compensação que corresponde melhor, penso eu, à realidade, está relacionada ao fato de que os fenômenos da compensação no campo da consciência foram estudados mais tardiamente do que em outros campos. A tarefa consiste em responder como surgem, então, os processos de desenvolvimento compensatório, quando eles não estão relacionados com a tomada de consciência, quando o defeito da função não é capaz de suscitar sentimentos de inferioridade e de deficiência, bem como a tomada de consciência dele. Não quero dizer que os fenômenos da compensação no campo da consciência equiparam-se aos fenômenos que ocorrem quando, por exemplo, se produz em uma pessoa um impulso diante da introdução de certa dose de veneno no organismo.

A teoria que quer dar uma explicação real aos fenômenos da compensação deve explicá-los em toda sua extensão e considerar que, até nos níveis mais baixos de desenvolvimento, os processos compensatórios estão ligados ao funcionamento da consciência. Aqueles autores que se veem obrigados a dar uma resposta, fazem-no no espírito do vitalismo, considerando que os elementos dos processos vitais têm um fator psicóide, algumas forças vitais do psiquismo que também movem os processos de compensação, isto é, que nos processos orgânicos de compensação está presente de forma não visível esse fator psicóide. Essa teoria baseia-se em um ponto de vista idealista, uma vez que tenta formular uma compreensão subjetivista da compensação.

Entretanto, até o estudo dos mais simples processos compensatórios do organismo e sua comparação com outros conduzem a uma afirmação baseada em fatos: a fonte, o estímulo primário para o surgimento dos processos compensatórios são as dificuldades objetivas com as quais a criança se depara no processo de desenvolvimento. Ela tenta contornar ou superar essas dificuldades com a ajuda de uma série de formações que originalmente não estão dadas em seu desenvolvimento. Nós observamos o fato de que a criança, ao se deparar com dificuldades, é obrigada a percorrer um caminho indireto para superá-las. Observamos que, do processo de interação da criança com o meio, nasce a situação que a impele a avançar pelo caminho da compensação. A mais importante evidência factual disso é a seguinte: o destino dos processos compensatórios e dos processos de desenvolvimento como um todo depende não apenas do caráter e da gravidade do defeito, mas também de sua realidade social, isto é, das dificuldades produzidas pelo defeito do ponto de vista da posição social da criança. Em crianças com deficiências, a compensação ocorre em direções completamente diferentes dependendo da situação criada, do meio em que a criança é educada, das dificuldades que surgem para ela a partir dessa deficiência. 
A questão das fontes do desenvolvimento compensatório está relacionada às reservas dessa compensação. De onde vêm as forças que são o motor do desenvolvimento compensatório? Para uma das teorias, a fonte é a intencionalidade interna do próprio processo vital de desenvolvimento, da integridade interna do indivíduo. Essa teoria passa diretamente a uma posição teleológica, ao propor que cada criança tem uma intencionalidade, um impulso vital, uma tendência interna, que a empurra inevitavelmente ao desenvolvimento, à plena autoafırmação, uma força vital instintiva que impele a criança adiante e garante seu desenvolvimento, independentemente de qualquer coisa.

Praticamente não resta dúvida de que os processos de desenvolvimento compensatório possuem uma intencionalidade objetiva, ou seja, utilizam funções úteis ao desenvolvimento da criança. Darwin ${ }^{7}$ já se confrontava com a tarefa de sua compreensão materialista, de sua explicação causal, isto é, a tarefa de mostrar como surge a intencionalidade objetiva desses processos. Diferentemente da teleologia, a maneira como examinamos a compensação não deriva da força do impulso interno; vemos que o recurso da compensação é, em grande medida, a vida social e coletiva da criança, a coletividade de seu comportamento, em que ela encontra material para a construção das funções internas surgidas no processo de desenvolvimento compensatório. É evidente que a abundância ou escassez dos recursos internos da criança, digamos, seu grau de atraso mental, constitui o aspecto essencial e primordial, determinante do quanto a criança é capaz de aproveitar esse material. E é evidente que o destino de um sujeito débil e de um idiota divergem essencialmente uma vez que seus recursos internos são profundamente diferentes. Esses recursos, afirmo novamente, não são determinantes nos estágios superiores, mas reiteradamente removidos no processo de desenvolvimento posterior da criança.

0 último aspecto que é preciso demarcar na compreensão básica dos processos de compensação é o seguinte: na clínica, conseguiu-se decifrar uma série de novas condições psicológicas e demonstrar que os sintomas patológicos podem surgir por um caminho compensatório. Com efeito, a compensação pode levar a criança por um caminho de nivelamento real ou fictício, falso, das deficiências; o aspecto central, que interessa aos pesquisadores na abordagem da compensação, é a distinção dessas duas linhas, a real e a fictícia, de compensação do desenvolvimento. A compensação como fonte de surgimento de aspectos complementares, úteis, não está sujeita à contestação, mas o aspecto compensatório pode ter também um caráter patológico. Isso também é verdadeiro. Metodologicamente é significativa a distinção dos sintomas complementares que surgem por meio da compensação e que normalizam, atenuam, nivelam a deficiência dos processos, levando o desenvolvimento dos sintomas da compensação fictícia para um estágio mais avançado.

Depois da breve discussão desses três aspectos, permitam-me passar diretamente a algumas posições básicas concretas que caracterizam o desenvolvimento compensatório da criança mentalmente atrasada.

A primeira é a amplamente conhecida substituição de funções, comuns para a criança normal e a anormal, e que possuem significado primordial. A questão é que as

7- 0 naturalista britânico Charles Darwin (1809-1882) foi uma das importantes fontes teóricas de Vigotski, que considerava sua teoria da evolução como fundamental para a compreensão do comportamento animal e da filogênese humana. 
operações psicológicas podem ser muito semelhantes no aspecto exterior, podem levar a um mesmo resultado, mas em sua estrutura, em sua natureza interna, naquilo que, como se diz, a pessoa realiza em sua cabeça, em sua relação causal, não possuir entre si nada em comum. Isso surge graças ao fato de que a maioria das funções psicológicas pode ser simulada, na expressão figurada de Binet, que foi o primeiro a fundamentar esse princípio, denominando-o simulação de funções psicológicas, por exemplo, simulação de uma memória excepcional. Como se sabe, Binet pesquisou pessoas com memória extraordinária e, além disso, distinguiu os sujeitos realmente dotados de memória excepcional daqueles com memória mediana. Esses últimos conseguiam reter na memória uma longa série de números ou palavras, muitas vezes superior ao que cada um de nós pode memorizar. Um sujeito com memória mediana substituía o processo de memorização pelo de combinação, de raciocínio. Quando lhe apresentavam uma longa série de números, ele os substituía por letras, imagens, palavras, relatos figurados; essa era a chave que lhe permitia recuperar os números e obter os mesmos resultados daqueles que realmente são dotados de memória excepcional, mas os obtinham por substituição. A esse fenômeno, Binet chamou de simulação da memória extraordinária.

Eu não teria começado a falar sobre isso se ocorresse apenas em casos excepcionais e não fosse a regra geral do desenvolvimento da criança, se não soubesse que, em cada um de nós, o êxito no desenvolvimento da memória se deve não apenas ao seu crescimento em si, mas também à aquisição de uma série de modos e procedimentos de substituição da memória. Há processos e operações psicológicas que a ampliam e conduzem a um nível elevado de desenvolvimento. Temos diante de nós não uma exceção, mas uma regra geral.

A substituição de certas operações psicológicas por outras é estudada no âmbito de quase todos os processos intelectuais. Apenas há relativamente pouco tempo os processos de substituição passaram a ser submetidos à avaliação clínica e pedagógica do ponto de vista de seu significado no desenvolvimento da criança atrasada. Pesquisas mostraram que habitualmente nenhuma das funções psicológicas (nem a memória, nem a atenção) se realiza de um modo único, mas todas elas se dão por diferentes modos. Consequentemente, onde há dificuldade, insuficiência, limitação ou simplesmente uma tarefa que ultrapassa as forças das possibilidades naturais de determinada função, ela não é mecanicamente anulada; mas emerge, é trazida à vida, realiza-se com a ajuda, por exemplo, daquilo que não tem a natureza de memorização direta, e transforma-se, então, em um processo de combinação, imaginação, pensamento e assim por diante.

Apresentarei uma tese geral que lhes permitirá avaliar em toda sua amplitude esse princípio de substituição das funções psicológicas, a diversidade das operações com a ajuda das quais as funções podem se realizar.

Vocês sabem que no desenvolvimento da memória ocorre uma mudança substancial aproximadamente no limiar da idade de transição: muda a correlação entre os processos de memorização, ou de memória, e os processos de pensamento. Para a criança de pouca idade, pensar significa lembrar, isto é, reproduzir situações anteriores. Essa tendência do processo de recordação fica particularmente clara quando propomos a tarefa de definir um conceito, principalmente se ele for abstrato. Vemos que a criança, em vez de dar uma definição lógica, reproduz uma situação concreta de sua experiência prévia. Já para o 
adolescente, lembrar significa pensar. 0 processo de recordação passa para o segundo plano e é substituído pela ordenação do pensamento.

Essa é uma tese geral que, como se pode ver, define uma etapa no desenvolvimento de funções isoladas e, ao mesmo tempo, consiste na forma mais simples com a qual se lida com o desenvolvimento da criança anormal em geral e da mentalmente atrasada em particular. Se lembrarmos como a criança cega lê ou como a surda-muda começa a falar, veremos que na base dessas funções está o princípio da substituição, que permite, por exemplo, falar não apenas com o auxílio de um mesmo mecanismo (isto é, do modo como nós falamos), mas também com a ajuda de outro. Ocorre que o modo habitual de funcionamento da fala não é o único e, quando ausente, ele pode ser substituído por outros.

Os meios auxiliares (fala, palavra e outros sinais) desempenham um papel decisivo nos processos de substituição em todo o desenvolvimento social da criança; com a ajuda deles a criança aprende a estimular a si mesma. 0 papel dos meios auxiliares, com os quais a criança se enriquece no processo de desenvolvimento, também conduz à segunda tese fundamental que caracteriza os processos compensatórios, à tese sobre o coletivo como fator de desenvolvimento das funções psicológicas superiores da criança normal e da anormal.

Permitam-me começar pela lei psicológica geral, que consiste em que uma série de funções psicológicas superiores percorrem os mais diversos caminhos; ela é mais facilmente compreensível pelo exemplo da origem e do desenvolvimento do pensamento como uma forma superior de relação com a linguagem. Vocês sabem que a linguagem se desenvolve inicialmente como meio de comunicação, de compreensão mútua, como função comunicativa, social. 0 discurso interior, isto é, o discurso com a ajuda do qual a pessoa pensa, surge mais tarde e há razão para se acreditar que o processo de sua formação se conclui apenas na idade escolar. 0 caminho de transformação da linguagem como meio de comunicação, como função do comportamento social e coletivo, em um meio de pensamento, em função psicológica individual, dá uma ideia sobre a lei que rege o desenvolvimento das funções psicológicas superiores. Essa lei pode ser assim enunciada: no processo de desenvolvimento da criança, toda função psicológica superior aparece duas vezes, primeiramente como função do comportamento coletivo, como organização da colaboração da criança com o meio circundante, depois como função individual do comportamento, como capacidade interior de atividade do processo psicológico no sentido mais estrito e exato dessa palavra. Precisamente da mesma forma a linguagem também passa de meio de comunicação a meio de pensamento. Novas pesquisas mostraram que exatamente assim o pensamento lógico, caracterizado pela busca de métodos de fundamentação de seus próprios julgamentos, aparece na criança de idade pré-escolar não antes do surgimento de discussões no coletivo infantil, da necessidade de expor os motivos de suas próprias afirmações. Como disse um dos pesquisadores, não apenas as crianças, mas também nós, adultos, acreditamos prontamente na palavra, ou seja, exigimos poucas evidências. A necessidade de reflexão lógica sobre as afirmações depende, na criança, do desenvolvimento de funções coletivas, como a função da discussão. 
Pesquisas mostraram que os processos volitivos mais característicos, os processos de subordinação, desenvolvem-se na criança também no coletivo. Pesquisadores ocidentais, em particular, registraram pela primeira vez nos dados das brincadeiras infantis que, durante o processo de brincadeira, surgem e se produzem na criança procedimentos de subordinação do próprio comportamento às regras do comportamento do coletivo. Depois, essa organização assim surgida transforma-se em função interior do comportamento e torna-se uma função psicológica própria.

Dessa forma, vemos que o comportamento coletivo da criança não apenas ativa e treina suas próprias funções psicológicas, mas é a fonte do surgimento de uma forma de comportamento completamente nova, aquela que surgiu no período histórico de desenvolvimento da humanidade e que, na estrutura da personalidade, se apresenta como função psicológica superior. 0 coletivo é a fonte do desenvolvimento dessas funções, particularmente na criança mentalmente atrasada.

0 caminho geral do desenvolvimento da linguagem infantil pode ser definido como uma forma coletiva quando dizemos que a criança dominou a linguagem. Depois, quando ela começa a controlar melhor seus próprios processos psíquicos, a linguagem passa a ser também um meio de pensamento. Pesquisas experimentais revelam diferenças entre o coeficiente de desenvolvimento dos processos psíquicos e seu real papel na vida da criança. É possível ter uma boa memória e utilizá-la mal e, ao contrário, é possível dominá-la de tal forma que seu efeito prático seja maior do que o de uma memória altamente desenvolvida, mas mal utilizada. Para a criança normal haverá um movimento ascendente, se em uma idade mais avançada o desenvolvimento se realizar não à custa do crescimento direto da função, mas à custa de sua utilização, de sua subordinação. 0 essencial é que uma série de funções psicológicas superiores vai do exterior ao interior. Assim como a linguagem serve de base para o desenvolvimento, também a forma exterior de colaboração coletiva é precursora do desenvolvimento de toda uma série de funções interiores. Aqui deparamo-nos com um aspecto essencial: a fonte, o meio que alimenta o desenvolvimento das funções psicológicas superiores, é o coletivo infantil, composto por crianças com certa diferença de nível intelectual ótimo. 0 pesquisador E. de Greeff aponta a particularidade da criança mentalmente atrasada: ela compreende melhor outra criança mentalmente atrasada, atribui-lhe maior valor do que a uma criança normal, pois lida com uma variação de nível que é capaz de superar. Na história do desenvolvimento da criança (e de nosso desenvolvimento psicológico), o funcionamento passivo supera significativamente a utilização ativa de qualquer função psicológica. A criança começa a compreender a fala antes de falar. Somos capazes de compreender um livro escrito por um gênio, mas frequentemente não temos condição de transmitir seu conteúdo: a possibilidade de nossa compreensão verbal é maior do que a possibilidade de utilização ativa da fala. A partir daí chegou-se a uma valiosa conclusão metodológica: para julgar corretamente as possibilidades de desenvolvimento e o nível real de desenvolvimento da criança atrasada, é preciso considerar não apenas quanto ela própria pode falar, mas também quanto ela pode compreender. Mas nós podemos compreender aquilo que está nos limites de nosso entendimento e isso é muito mais do que somos capazes de falar. 
A composição homogênea de um coletivo apenas por crianças mentalmente atrasadas, com nível de desenvolvimento altamente semelhante o mais parecido possível em relação ao nível de desenvolvimento, é um ideal pedagógico falso. Ele contradiz a lei fundamental do desenvolvimento do nível psicológico superior e a noção de diversidade e dinâmica das funções psicológicas da criança em geral e da mentalmente atrasada em particular. Pesquisadores anteriores acreditavam que o intelecto é uma função una, simples, monolítica, homogênea, e que, se temos diante de nós um débil, todas as suas funções estão uniformemente reduzidas. Uma investigação mais profunda mostrou: o intelecto, que surge no processo de desenvolvimento complexo, não pode ser uniforme por natureza, nem monolítico, indiferenciado, em sua estrutura. Ao contrário, aquilo que se denomina intelecto apresenta diversidade de funções em uma unidade complexa. Mas unidade não significa identidade, homogeneidade; o estudo da dinâmica dessa estrutura complexa levou os pesquisadores à seguinte conclusão: é impossível sustentar a tese de que, na situação de atraso, todas as funções do intelecto se mostrem igualmente afetadas, pois ao apresentar uma peculiaridade qualitativa, cada função afeta, também de forma qualitativamente peculiar, o processo que se encontra na base do atraso mental.

Darei um exemplo. Vocês sabem que apenas na última década foi estabelecida a verdadeira relação entre o desenvolvimento motor e o mental. Ficou claro que, frequentemente, determinadas formas se combinam, mas, para usar uma metáfora, não caminham obrigatoriamente de mãos dadas. Pesquisas subsequentes mostraram que o desenvolvimento das funções motoras pode ser, e na prática é, uma das esferas centrais da compensação da deficiência mental e vice-versa: no caso da criança com deficiência motora, com frequência ocorre acentuado desenvolvimento intelectual. A distinção e a compreensão da singularidade qualitativa das atividades intelectual, verbal, linguística e motora mostram que o atraso nunca afeta todas as funções intelectuais na mesma medida. A independência relativa das funções, em que pese sua unidade, resulta em que o desenvolvimento de uma função compensa e reverbera em outra.

\section{Dois últimos aspectos}

A observação da criança normal mostrou que o desenvolvimento das funções psicológicas ocorre não apenas à custa do crescimento e da mudança de uma função, por exemplo, da memória, da atenção etc. Uma vez que as funções nunca agem separadamente, mas sim em certa combinação, o desenvolvimento psicológico em uma idade mais avançada ocorre à custa de mudanças nas relações sistêmicas entre as funções, ou seja, à custa das chamadas ligações interfuncionais. No caso da chamada memória lógica, trata-se da conhecida relação entre memória e pensamento. No período inicial do desenvolvimento da criança, essas relações funcionais são diferentes daquelas do período posterior.

0 estudo da criança mentalmente atrasada mostrou que nela as relações interfuncionais se formam de um modo peculiar, diferente daquele observado no desenvolvimento das crianças normais. A esfera do desenvolvimento psicológico - a mudança das ligações e relações interfuncionais e da estrutura interna do sistema psicológico - é a principal esfera 
de aplicação dos processos compensatórios superiores da personalidade em formação. As ligações motoras e as relações interfuncionais caracterizam não tanto as próprias funções quanto o modo como elas resultam em uma unidade.

E, por fim, os caminhos indiretos de desenvolvimento, isto é, a realização ou o surgimento de algum novo ponto de desenvolvimento, de alguma nova formação pelo caminho indireto. Aqui o afeto tem enorme influência, estimulando a criança à superação das dificuldades. Se essas dificuldades não afastarem a criança, não a fizerem fugir delas, mas sim a mobilizarem, levarão então a um caminho indireto de desenvolvimento.

0 mais significativo é o caráter criativo do desenvolvimento da criança mentalmente atrasada. A pedagogia antiga supunha que causas externas afetavam automaticamente o caráter do desenvolvimento da criança mentalmente atrasada. Parecia que o emprego do expressivo termo criativo para essas pequenas conquistas alcançadas pela criança não seria correto. Na verdade, dominar as quatro operações aritméticas para o débil é um processo muito mais criativo do que para a criança normal. Aquilo que à criança normal é dado quase gratuitamente (sem formação), para a criança mentalmente atrasada apresenta dificuldade e exige a superação de obstáculos. Sendo assim, o processo de obtenção dos resultados parece ter um caráter criativo. Eu penso que isso é o que há de mais significativo no material sobre o desenvolvimento da criança mentalmente atrasada.

Na primeira parte, tentei delinear brevemente os processos no desenvolvimento da criança mentalmente atrasada que trabalham a nosso favor, nos quais devemos nos apoiar na tentativa de superar o atraso.

Mas seria um erro pensar que apenas esses aspectos completam o processo de desenvolvimento, que a sábia natureza conduz a criança pelo caminho da superação, lhe dá forças que ajudam a liquidar o atraso, assim como seria equivocado pensar que a luta do organismo com a doença sempre leva a um final feliz, que todo organismo, em quaisquer condições, a vence da mesma maneira.

É preciso dizer que as leis do desenvolvimento da criança anormal e da normal revelam-se diante de nós como uma lei essencialmente única. Um ambiente ruim e a influência que surge no processo de desenvolvimento da criança levam, com frequência e de forma aguda, a criança mentalmente atrasada a aspectos negativos adicionais, que não só não ajudam a superar o atraso, mas, ao contrário, acentuam, agravam sua deficiência original. É possivel perguntar: para que falar sobre esses processos, sobre o impacto do ambiente na criança mentalmente atrasada, se desde o início reconhecemos que, sob influência do caráter negativo no processo de desenvolvimento, na maior parte das vezes não apenas não se liquida o atraso da criança, mas se acrescentam novas particularidades?

É preciso falar sobre esses processos não somente porque a tarefa se mostra mais real diante de nós em sua totalidade de luz e sombra. Como procurarei demonstrar, no caso do atraso, costuma-se considerar como primordiais as complicações do desenvolvimento da criança que surgem no processo de sua formação no ambiente e que poderão ser superadas somente quando conseguirmos estudar profundamente suas causas. Isso tem um significado prático essencial. Mas trataremos disso depois.

A essência do pensamento que expressa o resultado de duas ou três décadas de trabalho científico coletivo nessa direção consiste no seguinte: o atraso mental não é 
um todo simples e homogêneo, como descrito por pesquisadores anteriores. Digamos que estou estudando uma criança mentalmente atrasada e estabeleço uma série de sintomas que revelam seu atraso. Pergunta-se: seriam todos esses sintomas equivalentes? Teriam eles uma mesma relação com a causa primordial? Seriam todos primordiais? Teriam todos surgido ao mesmo tempo, por meio de um mesmo mecanismo? Ou haveria entre eles sintomas principais e secundários, alguns surgidos antes e outros depois? Com base nos sintomas iniciais, quais seriam os principais tipos ou estratos da psicopatologia?

0 desenvolvimento mostra que o quadro pedagógico e psicológico do atraso mental que se revela diante de nós não é um todo homogêneo, que aqueles sintomas nos quais se evidencia o atraso não podem ser organizados em uma única série, que o atraso mental é uma estrutura complexa. Para examinar essa estrutura, é preciso voltarse ao desenvolvimento da criança mentalmente atrasada e não à natureza dos processos patológicos que estão em sua base, pois a complexidade da estrutura surge no processo de desenvolvimento. 0 exemplo central e mais simples de análise é a distinção entre as particularidades primordiais que compõem o próprio núcleo da debilidade - aqueles sintomas que derivam diretamente da deficiência biológica da criança, que estão na base de seu atraso - e os sinais de segunda, terceira, quarta, quinta, sexta ordem, e assim por diante, surgidos com base no fato de que a criança, durante sua formação em determinado meio, encontra dificuldades adicionais e acumula complicações adicionais. Os estratos que surgem sobre as formações originais levam à necessidade de diferenciar as pesquisas sobre o atraso mental.

Em relação à clínica, pode-se dizer que a oligofrenia é um grupo combinado. 0 estudo da estrutura da personalidade do oligofrênico foi primeiramente proposto no estudo do desenvolvimento infantil. Aqui, pela primeira vez, amadureceu uma ideia central para nosso trabalho: não basta dizer que uma criança é mentalmente atrasada (isso é o mesmo que dizer que está doente e não tratar); isso significa apenas colocar o problema, mas não o resolver. Em outras palavras, é preciso esclarecer que tipo de atraso cultural temos diante de nós, qual sua estrutura e significado, quais os mecanismos dos processos de construção dessa estrutura, qual o encadeamento dinâmico de seus sintomas e complexos isolados, a partir dos quais se forma o quadro do atraso mental da criança e a distinção dos tipos de crianças mentalmente atrasadas.

0 ingresso na escola auxiliar contemporânea ocorre pelo princípio da seleção negativa (A. Binet). Nossa escola auxiliar precisa trabalhar com um material bruto, com o atrasado mental em geral: nisso residem as principais dificuldades da abordagem e da diferenciação do atraso mental. A diferenciação deve tornar-se a regra básica de toda a nossa nova prática.

0 estudo das crianças mentalmente atrasadas mostra que o quadro que revelamos em relação a uma criança mentalmente atrasada de oito anos não pode de modo algum ser atribuído ao núcleo da debilidade, ou seja, à sua deficiência interna primordial. Permitam-me tomar o exemplo concreto com o qual comecei. As observações clínicas mostram que algumas crianças mentalmente atrasadas possuem discrepâncias, divergências extremas entre o desenvolvimento incompleto das funções psíquicas elementares e das superiores. 0 desenvolvimento incompleto manifesta-se de duas formas: pode ser que, no caso 
de pobreza geral no desenvolvimento das funções elementares, observe-se um desenvolvimento extraordinário das funções psíquicas superiores, que mascara o atraso mental da criança, ou então, o que se encontra mais frequentemente, um desenvolvimento desproporcionalmente fraco das funções psíquicas superiores em comparação com as orgânicas. Tomemos uma criança débil de dez anos. De acordo com o resultado dos testes, seu atraso mental é estimado em três anos, ou seja, ela está três anos atrasada em relação a uma criança normal; quer dizer, os dados finais sobre a criança devem mostrar um quadro similar ao apresentado por uma criança normal de sete anos de idade. Acontece que essa abordagem totalizante é incorreta. Se as funções psíquicas superiores na criança débil são muito menos desenvolvidas do que em uma criança de sete anos, então é preciso chegar à importante conclusão pedagógica de que o desenvolvimento incompleto das funções psíquicas superiores poderia ser suscetível à influência pedagógica, em contraste com o desenvolvimento das funções psíquicas elementares. Pesquisadores atentos formularam a seguinte pergunta: de onde surge o desenvolvimento incompleto desigual das funções inferiores, orgânicas, e das superiores, psíquicas? Se, no débil, o atraso no campo do desenvolvimento superior e inferior se originasse diretamente e de modo único a partir de uma causa primeira, a pergunta não surgiria. Essa desigualdade levou inicialmente à formulação empírica da questão: o desenvolvimento incompleto das funções superiores na criança débil deriva diretamente de uma causa original ou trata-se de uma complicação de segunda ordem? Dados experimentais e pesquisas clínicas ajudaram a encontrar a resposta. 0 desenvolvimento incompleto das funções superiores está ligado ao desenvolvimento cultural incompleto da criança mentalmente atrasada, à sua retirada do ambiente cultural, da nutrição do meio. Devido à deficiência, ela não vivenciou no momento adequado a influência do meio circundante e, em consequência disso, seu atraso se acumula, acumulam-se propriedades negativas e complicações adicionais na forma de um desenvolvimento social incompleto, de negligência. Tudo isso, na qualidade de complicações secundárias, revela frequentemente uma educação incompleta. $\mathrm{Na}$ situação em que ela cresceu, adquiriu menos do que poderia; ninguém tentou ligá-la ao meio. Quando a criança se relaciona pouco e pobremente com o coletivo infantil, complicações secundárias podem surgir.

Eu poderia mencionar uma série de grupos de sintomas que apresentam formações secundárias e terciárias na base do núcleo. Eu poderia mostrar o mecanismo causal de seu surgimento, mas agora limitar-me-ei a dizer que em todos os aspectos negativos que caracterizam a criança mentalmente atrasada, não temos simplesmente a passividade do desenvolvimento, a deficiência estabelecida desde o início. Sobre a criança agem, o tempo todo, princípios positivos e negativos. Sendo assim, acumula-se uma série de formações secundárias, que podem tanto seguir em direção ao nivelamento como provocar complicações adicionais no quadro primário do atraso mental.

Resta-me tirar uma conclusão pedagógica. Atualmente é necessário prestar atenção na segunda linha, na influência do meio sobre o desenvolvimento da criança mentalmente atrasada e, para isso, precisamos nos deter nas questões do acúmulo adicional de complicações do atraso mental. Isto tem enorme significado pedagógico e está estreitamente ligado com a tarefa prática que se coloca para a escola: reconhecer quais sinais são primários e quais 
são secundários. Pois, tudo o mais sendo igual, na solução do atraso mental, são mais facilmente eliminadas com a ajuda da ação pedagógica aquelas formações surgidas mais tarde, menos relacionadas com a causa original do fenômeno. Assim que se consegue provar cientificamente que determinado complexo de sintomas não é de primeira ordem, mas de segunda, terceira, quarta, quinta etc., demonstra-se que se criou um núcleo suscetível à ação pedagógica causal, ou seja, um núcleo que, tudo o mais sendo igual, pode ser mais facilmente removido quanto mais distante estiver da causa original.

Se falarmos de um grupo de crianças mentalmente atrasadas, cujo atraso tem em sua base uma deficiência patológica ou uma afecção cerebral, então o núcleo da própria debilidade e todos os fenômenos associados à deficiência se submetem com maior dificuldade à ação pedagógica, cedem apenas a uma ação constante, estimulante, indireta, de treinamento. Mas, uma vez que somos impotentes para remover a raiz dessa causa, então tampouco podemos remover os fenômenos relacionados com o núcleo. Ocorre exatamente o inverso quando falamos de complicações de segunda, terceira, quarta e quinta ordem. Elas se sobrepõem à complicação primária, são superadas em primeiro lugar e, como se expressa um dos autores contemporâneos, a superação de uma complicação secundária no mentalmente atrasado modifica todo o quadro clínico da debilidade em tal grau que a clínica contemporânea se recusaria a reconhecer a debilidade, caso o processo do trabalho educativo fosse levado até o final.

Resumindo o que falamos sobre a criança mentalmente atrasada e considerando como atraso tudo o que nela observamos, comporemos hoje um quadro clínico empírico. Ele cumprirá suas devidas funções, mas sem análise, sem distinguir aquilo que pertence ao núcleo do atraso e o que foi acumulado, adquirido. Será um quadro confuso; nele o secundário estará de tal modo relacionado ao primário que restringirá significativamente o campo de ação. 0 quadro empírico de modo algum coincidirá com o quadro real da debilidade, particularmente nos pontos em que os aspectos secundários foram, em certa medida, superados. Levenstein ${ }^{8}$ demonstrou experimentalmente que complicações adicionais são as mais suscetíveis à ação psicoterapêutica. Kretschmer ${ }^{9}$ confırmou clinicamente o padrão estabelecido por Levenstein: as complicações secundárias no processo de desenvolvimento da criança doente são as mais facilmente eliminadas.

Eu relaciono tudo isso a uma conclusão, que é a última das ideias que compõem esta apresentação e que distingue radicalmente as pedagogias contemporânea e tradicional sobre a infância mentalmente atrasada. Essa ideia é paradoxal: tudo leva-nos a crer que as funções superiores são mais suscetíveis à educação do que as elementares. A pedagogia antiga limitava o desenvolvimento da criança mentalmente atrasada. Depois passou-se a utilizar o método de treinamento sensório-motor: o treinamento dos olhos, dos ouvidos e a diferenciação de cores formavam metade do conteúdo do trabalho médico-pedagógico até

8- Não está claro a que autor Vigotski se refere aqui. A grafia do nome poderia ser Levenstein ou Lewenstein e a inicial do primeiro nome não remete a nenhum autor conhecido. A nota da edição russa diz "Levenstein, S.(?). A regularidade estabelecida por Levenstein sobre 0 fato de que as complicações secundárias no processo de desenvolvimento da criança enferma são as mais facilmente elimináveis está de acordo com as concepções de Vigotski".

9- Ernst Kretschmer (1888-1964) médico psiquiatra alemão, especialmente conhecido pela criação de uma tipologia que relaciona características físicas dos indivíduos a seus traços de caráter e temperamento. Vigotski utiliza os trabalhos desse autor principalmente como fonte para 0 estudo da anatomia do cérebro humano e das relações entre funções elementares e superiores. 
recentemente. Os resultados do treinamento sensório-motor são pobres. Pesquisas teóricas e experimentais demonstraram que o olfato, por exemplo, se desenvolve pouco e de forma muito frágil. As funções superiores, os processos superiores, são os mais suscetiveis à educação. Permitam-me apresentar dois argumentos teóricos que estão na base desse fenômeno e então o paradoxo será esclarecido.

A pesquisa experimental com gêmeos é um dos métodos contemporâneos que permitem distinguir as características hereditárias das condicionadas pelo meio social. A ciência utiliza um experimento que oferece maior possibilidade de aproximação de solução dessas questões. Como se sabe, os gêmeos podem ser monozigóticos ou dizigóticos. Todos passam pelo período intrauterino de desenvolvimento em um mesmo meio. Se compararmos dois pares de gêmeos - monozigóticos e dizigóticos - e determinarmos em que medida certas funções psíquicas são semelhantes, verifica-se que as funções $A$ (funções psíquicas superiores) de um e de outro par de gêmeos educados no mesmo meio apresentam um coeficiente de semelhança próximo. Isso significa que essas funções dependem pouco da hereditariedade e, portanto, dependem de determinadas condições de educação, do meio social. 0 coeficiente de semelhança das funções $B$ (funções psíquicas elementares) entre esses mesmos pares de gêmeos é diferente: essas funções mostram-se mais condicionadas hereditariamente do que as funções psíquicas superiores.

Pesquisas experimentais das funções motoras levam a uma tese geral: quanto mais elementares são os processos motores, mais distinto será o coeficiente de semelhança (em monozigóticos a semelhança é maior do que nos dizigóticos); quanto mais superiores as funções motoras, maior o coeficiente de semelhança entre os gêmeos de cada par, tudo o mais sendo igual. As funções motoras mais elevadas são mais suscetiveis à educação, porque elas não são filogenéticas, mas adquiridas na ontogênese. Os resultados das pesquisas experimentais mostram que os processos psicológicos superiores são mais suscetiveis à educação, pois a fonte do desenvolvimento de sua estrutura é a educação coletiva da criança.

Um dos alunos de Terman ${ }^{10}$, Quaid, realizou trabalhos experimentais na América e demonstrou que a dinâmica do desenvolvimento das funções elementares e das funções psíquicas superiores não é a mesma. 0 desenvolvimento da criança normal realiza-se principalmente à custa de processos superiores. 0 mesmo se observa nas crianças mentalmente atrasadas. Assim, a limitação do atraso mental ocorre à custa do desenvolvimento de processos superiores.

Gostaria de terminar com a indicação de que as conclusões, por mais que pareçam gerais e vazias, estão estreitamente ligadas às duas tarefas básicas que se colocam diante de nós e que devem provocar uma reviravolta em nossa escola auxiliar. Essas tarefas são a educação universal obrigatória e a politécnica. A antiga escola auxiliar refletia tendências e aspirações minimalistas. Por um lado, com a redução à educação elementar e a equiparação, no melhor dos casos, ao programa abreviado da escola de cinco anos, ela via um limite para o desenvolvimento e assim colocava em questão a possibilidade de aprendizagem e adaptação subsequente da criança. Por outro lado, essa escola baseavase em uma abordagem indiferenciada do atraso mental. Ela não distinguia complexos de

10- Lewis Terman (1877-1956), psicólogo norte-americano, desenvolveu uma versão revista do teste de inteligência de Binet-Simon. Dedicouse à investigação de crianças com alto escore em testes de QI. 
sintomas específicos do atraso mental de cada criança e, por isso, o tratamento pedagógico era construído como um todo único e homogêneo, sem distinção dos elos mais remotos e mais frágeis que poderiam ser os primeiros a serem rompidos e eliminados.

0 verdadeiro desenvolvimento da questão da educação geral e politécnica em relação às crianças mentalmente atrasadas deve ser objeto de uma investigação especial. Considero que atualmente é possível e necessário limitar-nos à indicação de que as conclusões obtidas de forma geral, as quais do ponto de vista teórico reconstroem a abordagem pedagógica tradicional voltada à criança mentalmente atrasada, estão estreitamente relacionadas às tarefas concretas e atuais que hoje se colocam para nossa escola. Porém, estabelecer essa ligação é tarefa para uma pesquisa à parte e está acima de minhas forças realizá-la sozinho.

Assim, seria o princípio da compensação o único a determinar a peculiaridade e as regularidades básicas do desenvolvimento da criança mentalmente atrasada? Não, ele não é o único, mas um entre muitos princípios e, obviamente, sua avaliação completa e abrangente e seu pleno desdobramento só são possíveis no conjunto e no sistema dos outros elementos que caracterizam o desenvolvimento como um todo.

Pergunta-se: será ele o principal, determinante? Depende do que estamos falando. Se for sobre o ponto de vista a respeito do qual falei na introdução, isto é, de transformar a orientação vitalista da pesquisa em uma orientação positiva, então a questão do método compensatório tem um significado determinante. E, desse ponto de vista, é necessário delimitar as fronteiras entre o princípio da compensação e os aspectos psicológicos subjetivos. Sobre isso já se falou e ainda será preciso falar adiante, quando estudarmos em detalhe as questões relacionadas a esse problema.

Seria esse o princípio organizador mais importante do trabalho? Claro que não. Tratase de um aspecto que indica o caráter do desenvolvimento, a categoria dos processos da criança atrasada, que tem regularidades, curso e destino peculiares. Será que isso significa que a tarefa imediata da pedagogia é o estudo dos processos compensatórios? Eu já disse que esses processos por si mesmos podem ser tanto a base para o nivelamento quanto a origem de uma série de novos sintomas patológicos. Por isso, penso que esse princípio, em seu aspecto geral, é uma forma sem conteúdo. Quando falamos da pedagogia e dos processos laborais, tomados no aspecto do ensino politécnico, ele torna-se o princípio básico e mais importante de todo o trabalho educativo. Mas será possível afirmar que o desenvolvimento da criança mentalmente atrasada é determinado somente pelos processos compensatórios? Não se pode colocar a questão dessa maneira. É importante esclarecer o que serve de ponto de apoio para o desenvolvimento integral da criança. Parece-me que há uma tarefa completamente determinada de decomposição, dissecação e análise dos processos que devem servir de ponto de apoio no desenvolvimento da criança, com os quais se deve trabalhar ao lidar com crianças atrasadas na escola politécnica.

Ao descrever como ocorre a substituição de algumas funções por outras, indiquei o fato de que estamos lidando com processos gerais inevitáveis de utilização máxima de todas as possibilidades. Se esse caminho inevitável de desenvolvimento é amplamente utilizado por crianças mentalmente atrasadas, isso significa que tal caminho do desenvolvimento é 
necessário e a questão da possibilidade da educação politécnica da criança mentalmente atrasada e de ela ter ou não capacidades que tornem essa educação realidade não é utópica.

Quando disse que a antiga orientação da pedagogia médica no treinamento predominante das funções elementares deve ser substituída pelo desenvolvimento mental das funções superiores na direção da sua máxima educabilidade, eu me referia às elevadas exigências que a educação politécnica apresenta.

Se surgir algum receio quanto à necessidade de salientar, enfatizar o desenvolvimento das funções superiores à custa das elementares, então é possível questionar: qual foi o resultado obtido pela escola quando ela seguiu exclusivamente a orientação do treinamento dos processos elementares, supondo que somente nesse campo a criança é capaz de se desenvolver? Vale mencionar o dogma da evidência que se apresenta de que a criança mentalmente atrasada é pouco apta ao desenvolvimento do pensamento abstrato e, por esse motivo, demonstra uma tendência ao pensamento figurativo e concreto. Será que devemos, como o fez a antiga escola tradicional, educar somente a partir de evidências, isto é, seguir a orientação da menor resistência, já que a criança mentalmente atrasada tem pouco sucesso no campo do abstrato? Devemos direcionar toda atenção para revelar e superar a deficiência onde ela se mostra mais patológica.

Resultados de pesquisas dos últimos dez anos e a aplicação do método sensóriomotor de M. Montessori ${ }^{11}$ mostraram que, no treinamento das funções elementares tanto em crianças normais quanto nas mentalmente atrasadas, seu desenvolvimento ocorre graças ao desenvolvimento das superiores. Quando o treinamento resulta no aumento da sensibilidade olfativa, surge na criança uma orientação atencional maior, uma análise mais minuciosa.

\section{2.}

Na vida da nossa escola auxiliar (para crianças mentalmente atrasadas), o novo ano letivo (1927) mostra-se crítico em certo sentido: a Glavsotsvos ${ }^{12}$ publicou os programas da escola auxiliar, construídos com base na última redação do programa da GUS ${ }^{13}$ para escolas municipais de nível inicial. Isso se deu depois de muitos anos de trabalho dedicados à aproximação entre a escola regular e a especial, ou melhor, à introdução dos princípios gerais da nossa educação social na escola especial e à reconstrução desta última nesses princípios. Essa tarefa de grande importância fundamental e prática foi resolvida por programas que engajam a escola auxiliar no âmbito da criação pedagógica geral. "Os objetivos e tarefas gerais que se colocam para a escola profissionalizante são também os objetivos e tarefas da escola auxiliar" (do Programa da Escola Auxiliar, 1927, p. 7). Essa tarefa de grande importância fundamental e prática foi resolvida por programas que engajam a escola auxiliar no âmbito da criação pedagógica geral. "Os objetivos e tarefas gerais que se colocam para a escola profissionalizante são também os objetivos e tarefas da escola auxiliar" (do Programa da Escola Auxiliar, 1927, p. 7). Essa formulação

11- Maria Montessori (1870-1952), médica e educadora italiana, conhecida por seu método de ensino focado no desenvolvimento da individualidade da criança e na base sensorial dos processos de aprendizagem.

12 -Главное управление социального воспитания (Glávnoie upravliênie sotsiálnogo vospitánia, Administração central da educação social).

13- Государственный учёный совет (Gosudarstviennyi utchionyi soviet, Conselho Científico Federal). 
oferece uma resposta perfeitamente clara à questão do caráter da escola auxiliar. Os princípios gerais da construção dos programas são exatamente os mesmos dos programas da escola regular; o objetivo imediato da escola auxiliar coincide com o da escola regular de nível inicial, na medida em que ela almeja educar o coletivo, "oferecer as habilidades e conhecimentos mais necessários para a atividade laboral e a vida cultural, e despertar nas crianças o interesse vivo pelo ambiente circundante" (op. cit.). Os programas merecem ser comentados de forma especial e detalhada.

Antes de tudo, algumas palavras sobre a aproximação da escola auxiliar e da regular. Em muitos países, a tendência a essa aproximação manifesta-se claramente. Deixem que as crianças mentalmente atrasadas estudem por mais tempo, que aprendam menos do que a crianças normais, e, enfim, sejam educadas de forma diversa, aplicandose métodos e procedimentos especiais adaptados às características particulares de sua condição, mas façam com que elas estudem o mesmo que as demais crianças, que recebam a mesma preparação para vida futura, para que, mais tarde, participem dela em pé de igualdade com as demais. Essa tendência pode ser expressa de forma mais simples. 0 mais importante argumento em favor de que as escolas auxiliares tenham, em geral, as mesmas tarefas da escola regular é a constatada e comprovada capacidade de trabalho da esmagadora maioria dos estudantes que terminam a escola auxiliar (90\%). Eles podem tomar parte do trabalho na sociedade não apenas em suas formas inferiores, como é o caso das crianças severamente atrasadas (imbecis), mas também no trabalho industrial, agrário e artesanal. Que outra educação é possível a esses futuros construtores e trabalhadores senão a educação social comum, recebida por todas as demais crianças do país?! De fato, os alunos da escola auxiliar devem ser introduzidos aos objetivos gerais por caminhos diferentes e nisto reside o sentido e a justificativa da existência de uma escola especial, nisto consiste toda a sua peculiaridade.

Tal tendência encontrou expressão em 1926, na Alemanha, onde foi levantada a questão sobre a alteração do nome da escola auxiliar (Hilfsschule). As crianças e os pais viam algo de ofensivo no nome antigo e a transferência para essa escola deixava um estigma na reputação da criança. Ninguém quer ir para a escola para tolos. 0 próprio fato de a criança passar por ela é percebido como rebaixamento de sua posição social. Adleristas dizem que ela desenvolve na criança o Minderwertigkeitsgefühl (sentimento de inferioridade), que reverbera de modo patológico no desenvolvimento geral. Mesmo sobre os professores dessa escola recai uma sombra da inferioridade. Foram sugeridas novas nomenclaturas: escola clínico-pedagógica, especial, escola médico-pedagógica. Por ora, não foi encontrado um nome apropriado. Provavelmente porque a questão não está apenas no nome, mas em toda condição pedagógica e social da escola auxiliar, de modo que ela não seja uma escola para tolos e que a educação oferecida por ela seja, não somente no nome, a educação social comum realizada no país. Nosso intento é explicitar a relação entre fenômenos vitais básicos (natureza, trabalho, sociedade), desenvolver nas crianças mentalmente atrasadas uma visão de mundo científica, trabalhar dentro da escola uma relação consciente dessas crianças com a vida futura.

A escola auxiliar tradicional segue a orientação da menor resistência, adaptando-se e acomodando-se ao atraso da criança: a criança atrasada tem maior dificuldade em dominar 
o pensamento abstrato, por isso, a escola exclui de seu material tudo que exige o esforço do pensamento abstrato e baseia a educação no concreto e no evidente. Atualmente, o princípio da absoluta supremacia do evidente está passando por uma séria crise, análoga à crise desse mesmo princípio na escola regular. De fato, será que a escola deve seguir a abordagem da menor resistência e somente adaptar-se ao atraso da criança? Ela não deveria, ao contrário, lutar contra o atraso, conduzir o trabalho em direção à maior resistência, isto é, à superação das dificuldades geradas pelo defeito no desenvolvimento infantil? W. Eliasberg ${ }^{14}$, ao estudar a psicologia e patologia da abstração, adverte corretamente contra a supremacia absoluta do evidente na escola auxiliar. Ao operar exclusivamente com concepções concretas e evidentes, prejudicamos e dificultamos o desenvolvimento do pensamento abstrato, cujas funções no comportamento da criança não podem de modo algum ser substituídas por procedimentos evidentes. É precisamente devido ao fato de que a criança atrasada tem dificuldade em chegar ao pensamento abstrato que a escola deve desenvolver essa capacidade de todas as maneiras possíveis. A tarefa da escola, no final das contas, não consiste em acomodar-se ao defeito, mas em superá-lo. A criança atrasada, mais do que a normal, precisa que a escola desenvolva nela os rudimentos do pensamento, uma vez que, por si mesma, ela não os domina. Nesse sentido, a tentativa de nossos programas de oferecer à criança mentalmente atrasada uma visão de mundo científica, revelar-lhe as relações entre fenômenos vitais básicos, conexões de ordem não concreta, trabalhar com ela na escola uma relação consciente com toda a vida futura é para a pedagogia médica uma experiência de significado histórico.

São bem conhecidas as dificuldades que o problema da cultura sensório-motora e da ortopedia técnica apresenta para a escola especial. 0 exercício dos órgãos sensoriais e motores da criança se transformou na escola tradicional em um sistema de aulas artificiais, isoladas, desinteressantes e, por isso, penosas para as crianças, como é o caso das aulas de silêncio, o estudo dos odores, a distinção dos ruídos etc. A saída, tanto para a escola estrangeira quanto para a nossa, está em diluir todos esses exercícios no jogo, no trabalho e em outras aulas. Por exemplo, um pomar e uma horta apresentam um campo ilimitado para todo tipo de exercícios, para o desenvolvimento dos sentidos e movimentos da criança. A observação meteorológica, a construção de barômetros e termômetros, a familiarização com a física elementar, o estudo da vida dos vegetais e dos animas, os rudimentos da ciência natural, a modelagem de formas vegetais e animais, a utilização de ferramentas de trabalho etc.: tudo isso pode ser concentrado em torno de um eixo, em torno do trabalho na horta, no jardim. Os exercícios sensório-motores, inseridos nesse fascinante trabalho, perdem seu caráter artificial e penoso para a criança.

14- Wladimir Eliasberg (1887-1969), médico alemão, estudou psiquiatria e psicanálise. Dedicou-se principalmente ao estudo de problemas de linguagem relacionados a questões neurológicas. 


\section{Referências}

KNOX, Jane; STEVENS, Carol. Vygotsky and Soviet Russian defectology: an introduction. In: RIEBER, Robert W.; CARTON, Aaron S. (Ed.). The collected works of L. S. Vygotsky: the fundamentals of defectology (Abnormal psychology and learning disabilities). v. 2. New York: Plenum Press, 1993. p. 1-25.

VIGOTSKI, Lev Semyonovich. K voprossu o kompensatornikh processakh v razvitii umstevenno otstalogo rebionka. In: VIGOTSKI, Lev Semyonovich. Sobranie sotchinienii v chesti tomakh. Moscou: Pedagoguika, 1983. p. 115-136.

VYGOTSKI, Lev Semyonovich. Acerca de los processos compensatórios em el desarrollo del niño mentalmente retrasado. In: VIGOTSKI, Lev Semyonovich. Fundamentos de defectologia. Tradução de Julio Guillermo Blank. Madrid: Visor, 1997. p. 131-152. (Obras escogidas; v. 5).

VYGOTSKY, Lev Semyonovich. Compensatory processes in the development of the retarded child. In: RIEBER, Robert W.; CARTON, Aaron S. (Ed.). The collected works of L. S. Vygotsky: the fundamentals of defectology (Abnormal psychology and learning disabilities). v. 2. New York, Plenum Press, 1993. Tradução de Jane E. Knox e Carol B. Stevens. New York, Plenum Press, 1993, p. 122-138. 